\title{
Oxidative stress in the etiology of age-associated decline in glucose metabolism
}

\author{
Adam B Salmon ${ }^{1,2}$
}

\begin{abstract}
One of the most common pathologies in aging humans is the development of glucose metabolism dysfunction. The high incidence of metabolic dysfunction, in particular type 2 diabetes mellitus, is a significant health and economic burden on the aging population. However, the mechanisms that regulate this age-related physiological decline, and thus potential preventative treatments, remain elusive. Even after accounting for age-related changes in adiposity, lean mass, blood lipids, etc., aging is an independent factor for reduced glucose tolerance and increased insulin resistance. Oxidative stress has been shown to have significant detrimental impacts on the regulation of glucose homeostasis in vitro and in vivo. Furthermore, oxidative stress has been shown to be modulated by age and diet in several model systems. This review provides an overview of these data and addresses whether increases in oxidative stress with aging may be a primary determinant of age-related metabolic dysfunction.
\end{abstract}

Keywords: Oxidative stress, Insulin resistance, Muscle, Adipose, Mitochondria, Inflammation

\section{Review}

\section{Introduction}

The aging process is associated with functional declines in nearly every physiological parameter measured to date [1]. One of the most common physiological declines in human aging is a general deficit in the ability to effectively regulate glucose metabolism. The prevalences of elevated fasting glucose levels, glucose intolerance, and insulin resistance have all been shown to be significantly elevated in the aged population [2-5]. Indeed, one of the most common diseases of the elderly is type 2 diabetes mellitus. The NIH estimated that in 2010 approximately $4 \%$ of people aged 20-44 in the United States were affected by type 2 diabetes; in contrast, in this same period $26.9 \%$ of people older than 65 , or 11 million Americans, were suffering from this disease. Determining how aging so powerfully affects the progression of this disease could lead to potential prevention and reduction in the aged population.

\footnotetext{
Correspondence: salmona@uthscsa.edu

${ }^{1}$ The Geriatric Research Education and Clinical Center, South Texas Veterans Health Care System, Audie L. Murphy Hospital, San AntonioTX 78229, USA

${ }^{2}$ Department of Molecular Medicine, The Sam and Ann Barshop Institute for Longevity and Aging Studies, The University of Texas Health Science Center at San Antonio, 15355 Lambda Drive, MSC 7755, San Antonio, TX
} 78245-3207, USA
Aging in mammals is generally associated with accumulating adipose tissue, diminishing lean mass and elevated blood lipids, all of which are associated with the development of insulin resistance. Even after controlling for these confounds, aging alone is an independent factor in the declining response to insulin in skeletal muscle and other tissues [6-8]. In a longitudinal study of over 4,500 healthy individuals, Lindstrom et al. showed the likelihood of patients 55-64 years of age for developing drug-treated diabetes was roughly equivalent to patients with a BMI $>30$ [9]. In other words, clinical obesity and advanced age present nearly the same risk of causing metabolic dysfunction. This is particularly worrisome when considering that several diabetes risk factors (obesity, hyperglycemia, etc.) have straightforward treatment options whereas aging is a persistent, unyielding process. The mechanisms that regulate the effects of aging on glucose metabolism have not yet been clearly identified. Recent evidence has suggested that oxidative stress may be an important factor in this process. The Oxidative Stress Theory of Aging has been one of the most prominent mechanistic theories on how the aging process is regulated. Most studies in this field have shown little effect of oxidative stress on mammalian lifespan, but there is clear evidence that oxidative 
stress can promote the development of many agerelated diseases and pathologies [10].

Oxidative stress is a necessary byproduct of life in aerobic environments. Oxygen free radicals are generated through several cellular processes, the most significant of which occurs with aerobic respiration in the mitochondria. In the presence of molecular oxygen, the reactions that generate ATP in the electron transport chain complexes of the mitochondria can generate oxygen free radicals [11]. However, aerobic organisms have evolved a complex antioxidant defense system to reduce free radicals, prevent oxidative damage, and repair oxidative damage that does occur [10]. An exhaustive review of all cellular pro-oxidant and antioxidant sources are beyond the scope of this review. At the most basic level, oxidative stress occurs under conditions that favor factors that generate oxygen free radicals (pro-oxidants) rather than those factors that evolved to reduce these radicals (antioxidants). In contrast, conditions that favor reduction of free radicals, for example by increasing cellular antioxidants, would be predicted to reduce oxidative stress under normal physiological conditions. The remainder of this review will provide support for the hypothesis that age-dependent alterations in this balance promote oxidative stress which causes metabolic dysfunction.

\section{Oxidative stress causes metabolic dysfunction}

Several studies have shown that oxidative stress can directly promote cellular insulin resistance and alter glucose metabolism. In cell culture, oxidative stress dramatically decreases the cellular response to insulin. In these studies, treatment with oxidative stress significantly reduced insulin-stimulated glucose uptake, reduced phosphorylation of the downstream insulin signaling mediators protein kinase B (AKT), insulin receptor substrate protein-1 (IRS-1), and glycogen synthase kinase-3, and reduced glucose transporter (GLUT4) translocation to the cellular membrane [12-16]. Similarly, glucose transport was reduced in ex vivo rat muscle following oxidative stress $[17,18]$. Chronic $\mathrm{H}_{2} \mathrm{O}_{2}$ treatment of ex vivo muscle also inhibited insulin-stimulated phosphorylation of the insulin receptor and AKT and caused a selective loss of IRS proteins which further inhibited insulin response [18]. Furthermore, treatment with antioxidants prevented the development of insulin resistance in both cell culture and ex vivo experimental models $[15,16,18]$. Antioxidants also partially prevented cellular insulin resistance caused by tumor necrosis factor-alpha (TNF $\alpha$ ), glucocorticoids, and the saturated fatty acid palmitic acid, suggesting that oxidative stress plays a key role in their action on glucose metabolism $[19,20]$. Together, these data show that oxidative stress can both directly and indirectly inhibit glucose metabolism.
There is also strong evidence that elevated levels of oxidative stress are correlated with defects in glucose metabolism in both human clinical studies and laboratory models. For example, urinary levels of the DNA oxidation marker 8-oxo-2'-deoxyguanosine (8-OHdG) and plasma levels of the lipid oxidation marker malondialdehyde (MDA) are significantly elevated in diabetic patients [21-23]. One interpretation of this is that hyperglycemia with metabolic dysfunction may promote oxidative stress $[24,25]$. However, even prediabetic patients show elevated urinary levels of 8OHdG suggesting that oxidative stress may precede the clinical development of glucose intolerance, insulin resistance and diabetes [26]. Similarly, Tinahones et al. found the degree of insulin resistance among obese patients was positively correlated with plasma lipid peroxidation levels and inversely correlated with plasma antioxidant levels [27]. Furthermore, defects in glucose metabolism are associated with both reduced levels of antioxidants (glutathione and vitamin $\mathrm{E}$ and $\mathrm{C}$ ) as well as reduced activity of antioxidants (superoxide dismutase, glutathione peroxidase, and glutathione reductase) in plasma [27-32]. Together, these findings hint that oxidative stress may act as both cause and effect of metabolic dysfunction in a vicious cycle towards developing diabetes.

Though there is a clear association between oxidative stress and the pathological state of diabetes (or prediabetes), the association between oxidative stress and ageinduced metabolic dysfunction is less clear. Samiec et al. reported that plasma levels of the antioxidant glutathione from healthy individuals older than 60 years are greater than those of younger diabetics but less than those of healthy younger individuals [30]. Interestingly, this study also reported that levels of the oxidized form of glutathione (GSSG) were relatively high in both healthy older and diabetic individuals [30]. Similarly, Nuttal et al. found that plasma lipid hydroperoxide levels were highest in elderly diabetics ( $\sim 75$ years old) followed by healthy elderly ( $\sim 70$ years old) with the lowest levels were reduced in healthy young individuals [33]. This study also showed total antioxidant capacity and glutathione levels were reduced in both elderly diabetics and healthy elderly compared to healthy young [33]. Mendoza-Nunez et al. showed that both diabetes and aging are risk factors for increased oxidative stress with an additive effect of both phenotypes [34]. Even among diabetic patients, markers of plasma oxidative stress significantly increase with age [35]. This trend is also evident in laboratory mice; Wu et al. found that protein oxidation and activation of oxidative stress-sensitive pathways were elevated in both young diabetic and old mice and elevated further still in old diabetic mice [36]. Examining whether oxidative stress and/or damage is associated with mild agerelated metabolic defects, rather than frank diabetes, is an 
important next step to support the hypothesis of this review.

\section{Oxidative stress accumulates with age in tissues that regulate glucose metabolism}

Glucose metabolism in mammals is regulated by a complex set of endocrine signals that ultimately affect insulin release from the pancreas, glucose production from the liver, and glucose uptake in peripheral tissues including skeletal muscle, adipose, liver, brain, and cardiac muscle. Development of insulin resistance in skeletal muscle, white adipose tissue, and liver is generally thought to be the primary etiology of glucose metabolism dysfunction. The insulin response in each of these tissues shows a significant decline with age [2,3,37]. If oxidative stress is a significant contributor to this process, it would be predicted that elevated levels of oxidative stress/damage in these tissues would be associated with 1) metabolic dysfunction and 2) increasing age.

As discussed above, there is strong evidence supporting the first prediction; that is, circulating levels of oxidative stress are generally elevated in vivo in experimental models of metabolic dysfunction. There is also strong evidence for increased oxidative stress in the tissues of these models. Obesity, whether caused by genetic factors or high fat/high caloric diets, diminishes insulin sensitivity and increases oxidative stress in rodents and humans [38]. For example, skeletal muscle and adipose tissue of high-fat-fed laboratory mice show high levels of protein oxidation as measured by total levels of proteins bound with carbonyl or 4-HNE (4-hydroxenonal) adducts [39,40]. Similarly, lipid oxidation levels are also elevated in these tissues from high fat fed mice and rats [38,41]. Moreover, skeletal muscle mitochondria production of superoxide and hydrogen peroxide is significantly increased with high fat feeding $[42,43]$ as is superoxide production from NADPH oxidase activity in adipose tissue [38]. There is limited data on oxidative stress/damage in tissues from human subjects due to the challenges in obtaining samples. However, obesity in humans is associated with increased protein oxidation adducts in subcutaneous adipose tissue and skeletal muscle [44,45]. Together, these findings show that reduction in glucose metabolism in rodents and humans is strongly associated with oxidative stress.

Since the development of the Oxidative Stress Theory of Aging over 50 years ago, there have been extensive efforts to address whether accumulating oxidative damage (including that in muscle, liver and adipose tissue) is a significant modulator of the aging process [46]. Old mice do have increased levels of DNA, lipid and protein oxidation in skeletal muscle [47-49] and mitochondria from muscles of old mice produce more hydrogen peroxide than those from young mice [47].
Similarly, muscle biopsies from healthy older human subjects show increased levels of lipid peroxidation and reduced levels of several antioxidants [50]. Liver and visceral adipose have also been reported to accumulate lipid and protein oxidative damage with age in both mice and rats $[48,51-55]$.

Oxidative stress might also negatively affect glucose metabolism at the level of insulin release from the $\beta$-cells of the pancreas. In comparison to other tissues, the relative expressions of the antioxidants superoxide dismutases (both the cytosolic $\mathrm{Cu} / \mathrm{Zn} \mathrm{SOD}$ and mitochondrial $\mathrm{Mn}$ SOD), glutathione peroxidases, and catalase are reduced in islet cells [56,57]. A blunted antioxidant defense may be beneficial in these cells because reactive oxygen species are required for normal $\beta$-cell response to glucose $[58,59]$. However, this phenotype also renders pancreatic $\beta$-cells particularly sensitive to the negative effects of oxidative stress. For example, streptozotocin, a toxin selective to $\beta$-cells used to create diabetic rodents, works in part by generating oxidative stress [60,61]. Several antioxidant treatments have been shown to prevent streptozotocininduced $\beta$-cell death [60-62]. Furthermore, genetic overexpression of antioxidants has been shown to protect the pancreas in diabetic models [63]. While the effect of aging on oxidative damage in the pancreatic cells has not yet been addressed, there are several reports of increased oxidative damage in this tissue with metabolic dysfunction $[60,61,64,65]$.

It is likely that all tissues are targets of oxidative damage in metabolic dysfunction and/or aging; however, there is evidence that adipose may be more susceptible to, or generate more, oxidative stress than others. Until recently, white adipose tissue was thought to be a largely inert, energy storing tissue. However, adipose tissue is a dynamic endocrine organ and changes in its function may play a significant role in the aging process in mammals [66]. White adipose tissue, particularly visceral adipose, is characterized as highly inflammatory. Aging significantly increases the production of proinflammatory cytokines from macrophages and pre-adipocytes in this tissue [6769]. Our own data show that oxidative damage is higher in visceral adipose than either skeletal muscle or liver even at a young age. Levels of lipid peroxidation (measured by $\mathrm{F}_{2}$-isoprostanes) in young male $\mathrm{C} 57 \mathrm{BL} / 6$ mice were more than two-fold higher in visceral adipose compared to muscle and liver (Figure 1). Levels of protein oxidation (measured by methionine sulfoxides) in adipose tissue were also significantly greater than in muscle or liver (Figure 1). Furthermore, modulation of oxidative stress in this tissue is extremely responsive to environmental conditions. Induction of metabolic stress by high fat feeding dramatically increased both of these markers in adipose tissue with more modest changes in both muscle and liver (Figure 1). 


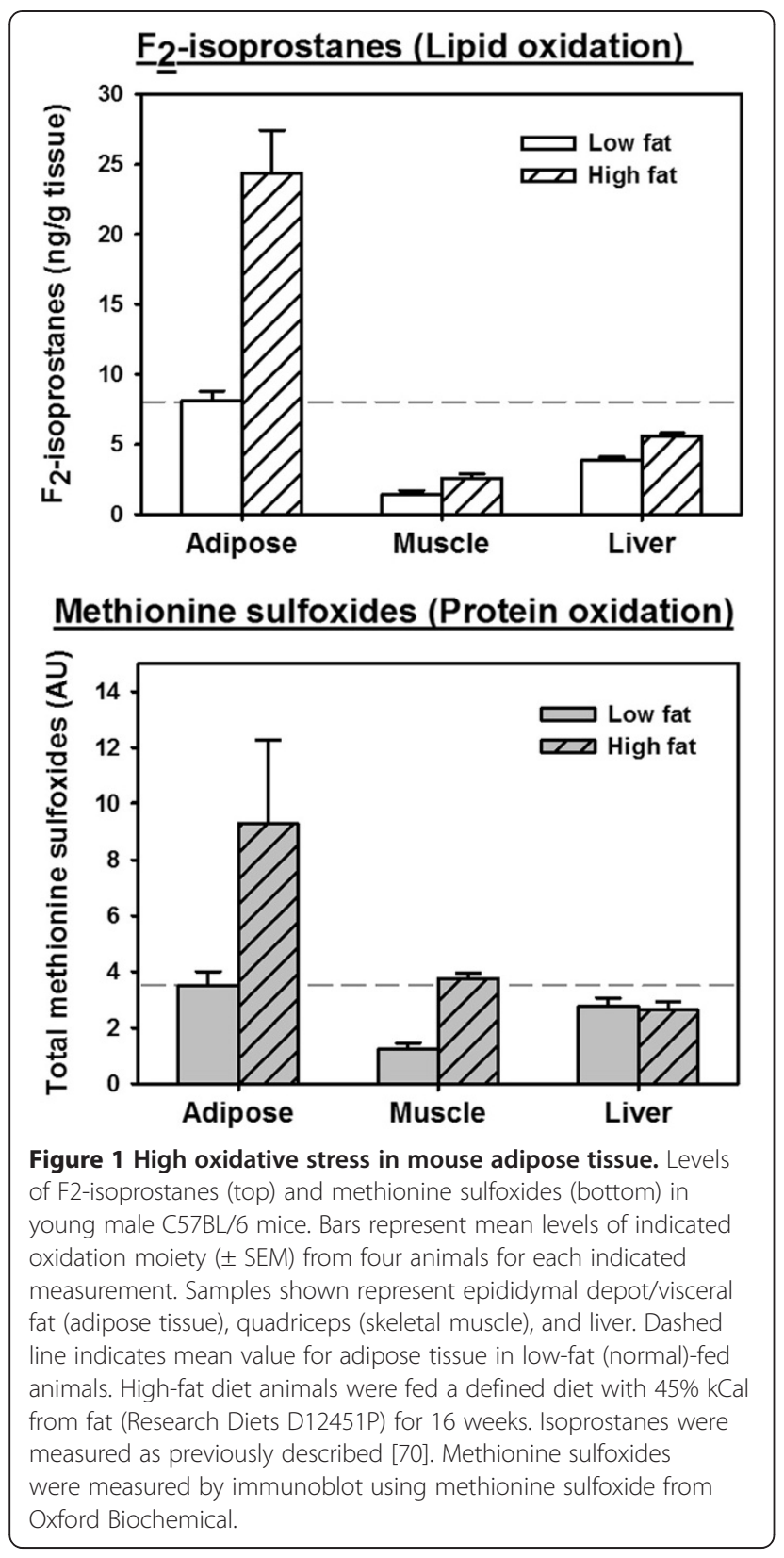

How does oxidative stress promote metabolic dysfunction?

Oxidative stress may exert its effects on glucose metabolism through three primary pathways: (1) by activation of stress-responsive signaling pathways, (2) by promotion of proinflammation and (3) by directly affecting the insulin signaling pathway. For the purposes of this review, these pathways have largely been studied for their effect on reduction of insulin signaling. For example, activation of the c-jun $\mathrm{N}$ terminal kinase (JNK) signaling pathway has been implicated in the etiology of diabetes and insulin resistance, particularly that caused by obesity [71]. Activation of JNK, in particular the
JNK1 isoform, phosphorylates IRS-1 at sites that prevent its recruitment to the activated insulin receptor thus preventing propagation of insulin signaling and promoting insulin resistance $[72,73]$. Oxidative stress can activate JNK signaling both directly and indirectly through several kinase pathways [74-76]. JNK activation is significantly upregulated in obesity and metabolic dysfunction; further, genetic ablation of JNK in mice (either whole body or liver-specific) prevents dietary- and geneticallyinduced insulin resistance $[77,78]$. Several tissues have been reported to show elevated JNK activation with aging in both rodents and humans $[79,80]$.

Chronic inflammation has been proposed to significantly influence the progression of several age-related diseases and pathologies, including the decline in glucose metabolism homeostasis $[71,81,82]$. Oxidative stress promotes the production of several pro-inflammatory cytokines including interleukin-6 (IL-6) and monocyte chemotactic protein in cells [83]. Oxidative stress can also activate nuclear factor $\mathrm{\kappa B}(\mathrm{Nf} \mathrm{kB})$, a transcription factor that regulates production of TNF $\alpha$ and IL-6 $[84,85]$. Oxidative stress also promotes cellular senescence, particularly in adipocytes; these senescent cells can then promote localized inflammation by secreting proinflammatory cytokines and by recruiting macrophages [86-88]. TNF $\alpha$ and IL-6 have been shown to inhibit insulin signaling through inhibitory phosphorylation of IRS1; ablation of these cytokines prevents insulin resistance in cells and in vivo $[89,90]$. Aging is a significant factor in the increased expression of multiple proinflammatory cytokines including TNF $\alpha$ and IL-6 [67,91]. Furthermore, aging has been shown to prevent the normal suppression of TNF $\alpha$ that occurs postprandially [92].

It is also possible that oxidative stress may directly cause insulin resistance by damaging cellular components required for proper insulin signaling. Oxidative stress impairs binding of insulin to the insulin receptor and reduces cellular internalization of insulin, presumably by promoting oxidative damage at its binding site [93]. Similarly, Zhou et al. and Van den Dobbelsteen et al. showed that high doses of peroxynitrite or redoxcycling agents can inhibit the ability of insulin receptor to undergo autophosphorylation $[94,95]$. Oxidative stress disrupts the insulin-stimulated cellular redistribution of IRS1 and phosphoinositide 3-kinase required for efficient transduction of insulin signaling, GLUT4 translocation and glucose uptake [96]. In addition, GLUT4 levels decrease with oxidative stress because of oxidative damage to nuclear proteins regulating its expression [97]. It has been suggested that age-associated insulin resistance is partly due to diminished function of insulin signaling proteins [98]. Proteins that undergo oxidation have clear and marked declines in function largely due to changes in their structural conformation 
$[99,100]$. It still remains to be determined whether the decline in insulin signaling function can be ascribed to this biochemical process.

\section{Can antioxidants prevent metabolic dysfunction in vivo?} If oxidative stress is a significant cause of glucose intolerance/insulin resistance, antioxidant treatments would be predicted to prevent metabolic dysfunction. In rodent models, there is substantial evidence supporting this hypothesis. For example, treatment of mice with the mitochondria-targeted superoxide dismutase mimetic MnTBAP prevented the development of insulin resistance and glucose intolerance caused by high fat diet feeding [101]. MnTBAP treatment also improved glucose homeostasis in genetically obese mice [19]. Rats treated with a different mitochondria-targeted small molecule antioxidant, SS31, showed a similar protection from high fat diets [42]. Several genetic models of increased antioxidant expression have also been shown to protect from obesity-induced insulin resistance; overexpression of Mn-superoxide dismutase, catalase (specifically in mitochondria; mCAT) and peroxiredoxin 3 have all been shown to preserve glucose homeostasis with high fat feeding $[42,101,102]$. Antioxidant treatments have also been suggested to prevent age-associated metabolic dysfunction in rodent models. Lee et al. showed that mCAT mice are protected from age-associated declines in insulin due to due to reduced mitochondrial $\mathrm{H}_{2} \mathrm{O}_{2}$ production and reduced accumulation of oxidative damage [103]. Long-term treatment of rats with the antioxidants vitamin $\mathrm{C}$ or butylated hydroxytoluene improved the insulin response of adipocytes isolated from old animals [104].

Despite the strong evidence that antioxidants may be beneficial for glucose metabolism in rodents, most studies on antioxidant therapy in humans have been largely inconclusive. Classical antioxidant therapies, such as vitamin $C$ and vitamin $E$, appear to have little effect on metabolic dysfunction of several forms [105]. Other antioxidants such as coenzyme Q10, alpha-lipoic acid, and L-carnitine have also been largely ineffective as treatments [106]. Because these clinical studies only treated individuals exhibiting diabetes or pre-diabetes, one interpretation may be that these treatments cannot reverse metabolic dysfunction. If oxidative stress precedes the development of glucose tolerance and insulin resistance [26], it may be more apt to utilize antioxidants as a preventative as in many of the rodent studies above. Furthermore, issues of dosage and bioavailability in target tissues are significant confounds in these studies [107]. For example, because of the high lipid levels in adipose, this highly oxidized tissue may not be strongly affected by water-soluble antioxidants. New insights into the mechanisms by which oxidative stress negatively affects glucose metabolism may provide new antioxidants, or treatment regimes, that can prevent agerelated metabolic dysfunction.

\section{Conclusions}

The high incidence of metabolic dysfunction in the aged population is a significant health and economic burden on a growing population. The population growth of both individuals over 65 years of age and obese individuals suggests that this problem will not diminish without significant intervention. While improving diet, increasing aerobic exercise and weight loss can all improve glucose metabolism, aging remains an independent factor in the development of insulin resistance [6-8]. Understanding this process could significantly improve both health span of the aging individual and health of the elderly population. How oxidative stress may fit into this process is summarized in Figure 2. Regulating oxidative stress does make for an attractive treatment target; the process is well studied, there are precise assays for its measurement, and there are viable treatments, such as antioxidants, that reduce its effects.

While experimental evidence has suggested that antioxidant treatments can prevent metabolic dysfunction caused by diet or aging in rodents, clinical studies have largely failed. Some potential rationales for these discrepancies have been described above. However, the benefit of healthy diet, activity and lifestyle on reducing

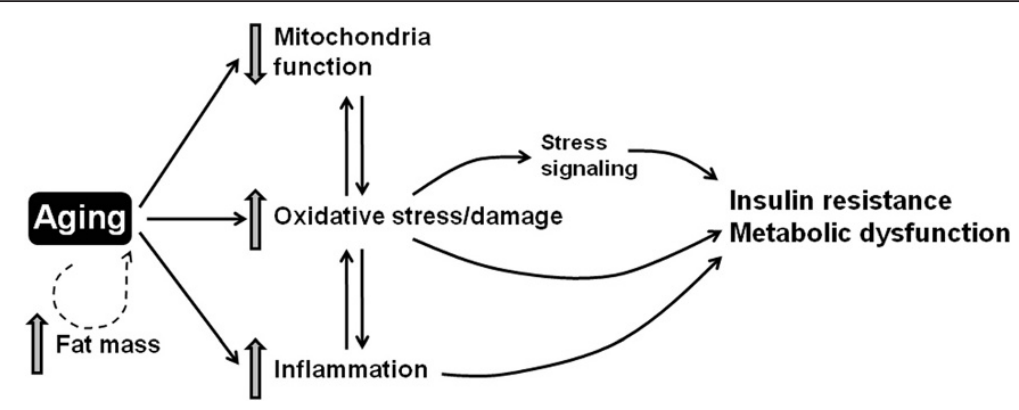

Figure 2 Proposed model illustrating the potential links between aging, oxidative stress, and metabolic dysfunction. 
oxidative stress in vivo cannot be discounted as a means to at least slow the progression of metabolic defects [108-113]. As mentioned above, studies in rodents suggest that there may be some benefit to increasing antioxidant levels as anti-diabetic prophylactic treatment rather than clinical treatment $[19,42,101]$. Support would require long-term longitudinal studies to determine whether these treatments would be preventative. In the short-term, new insights into the mechanisms by which oxidative stress negatively affects glucose metabolism may develop new antioxidants, or treatment regimes, that can prevent age-related metabolic dysfunction. For example, new treatments that specifically target muscle or adipose tissue may have much stronger effects on glucose metabolism at lower doses than more general antioxidants. The goal of these studies should not be to find alternatives to healthy living, but rather to utilize treatments in conjunction with healthy lifestyles to extend the health span in humans.

\section{Abbreviations}

8-OHdG: 8-Oxo-2'-deoxyguanosine; AKT: Protein kinase B; GLUT4: Glucose transporter 4; IL-6: Interleukin-6; IRS-1: Insulin receptor substrate protein-1; JNK: C-jun N terminal kinase; MDA: Malondialdehyde; NfkB: Nuclear factor $\mathrm{KB}$; TNFa: Tumor necrosis factor alpha.

\section{Competing interests}

The author declares no financial competing interests.

\section{Acknowledgments \\ This work was supported by an NIA training grant for the basic biology of aging (AG021890-05) and the Geriatric Research, Education, and Clinical Center of the South Texas Veterans Health Care System, Audie L. Murphy Hospital. F2-isoprostane measurements were performed by the Nathan Shock Center oxidative stress and mitochondrial function core facility at UTHSCSA.}

Received: 11 May 2012 Accepted: 9 July 2012

Published: 1 November 2012

\section{References}

1. Finch C: Longevity, Senescence and the Genome. Chicago, L: University of Chicago Press; 1994.

2. Defronzo RA: Glucose intolerance and aging: evidence for tissue insensitivity to insulin. Diabetes 1979, 28:1095-1101.

3. DeFronzo RA: Glucose intolerance and aging. Diabetes Care 1981, 4:493-501.

4. Kohrt WM, Kirwan JP, Staten MA, Bourey RE, King DS, Holloszy JO: Insulin resistance in aging is related to abdominal obesity. Diabetes 1993 42:273-281.

5. Fink RI, Kolterman OG, Griffin J, Olefsky JM: Mechanisms of insulin resistance in aging. J Clin Invest 1983, 71:1523-1535.

6. Karakelides H, Irving BA, Short KR, O'Brien P, Nair KS: Age, obesity, and sex effects on insulin sensitivity and skeletal muscle mitochondrial function. Diabetes 2010, 59:89-97.

7. Jackson RA, Hawa MI, Roshania RD, Sim BM, DiSilvio L, Jaspan JB: Influence of aging on hepatic and peripheral glucose metabolism in humans. Diabetes 1988, 37:119-129.

8. Gabriely I, Ma XH, Yang XM, Atzmon G, Rajala MW, Berg AH, Scherer P, Rossetti L, Barzilai N: Removal of visceral fat prevents insulin resistance and glucose intolerance of aging: an adipokine-mediated process? Diabetes 2002, 51:2951-2958.

9. Lindström J, Tuomilehto J: The diabetes risk score. Diabetes Care 2003, 26:725-731.
10. Salmon $A B$, Richardson $A$, Perez VI: Update on the oxidative stress theory of aging: does oxidative stress play a role in aging or healthy aging? Free Radic Biol Med 2010, 48:642-655.

11. Cadenas E, Boveris A, Ragan Cl, Stoppani AO: Production of superoxide radicals and hydrogen peroxide by $\mathrm{NADH}$-ubiquinone reductase and ubiquinol-cytochrome c reductase from beef-heart mitochondria. Arch Biochem Biophys 1977, 180:248-257.

12. Gardner CD, Equchi S, Reynolds CM, Eguchi K, Frank GD, Motley ED: Hydrogen peroxide inhibits insulin signaling in vascular smooth muscle cells. Exp Biol Med 2003, 228:836-842.

13. Maechler $\mathrm{P}$, Jornot $\mathrm{L}$, Wollheim CB: Hydrogen peroxide alters mitochondrial activation and insulin secretion in pancreatic beta cells. J Biol Chem 1999, 274:27905-27913.

14. Dokken BB, Saengsirisuwan V, Kim JS, Teachey MK, Henriksen EJ: Oxidative stress-induced insulin resistance in rat skeletal muscle: role of glycogen synthase kinase-3. Am J Physiol Endocrinol Metab 2008, 294:E615-E621.

15. Maddux BA, See W, Lawrence JC Jr, Goldfine AL, Goldfine ID, Evans JL: Protection against oxidative stress-induced insulin resistance in rat L6 muscle cells by mircomolar concentrations of alpha-lipoic acid. Diabetes 2001, 50:404-410

16. Singh I, Carey A, Watson N, Febbraio M, Hawley J: Oxidative stress-induced insulin resistance in skeletal muscle cells is ameliorated by gamma-tocopherol treatment. Eur J Nutr 2008, 47:387-392.

17. Henriksen EJ, Holloszy JO: Effect of diffusion distance on measurement of rat skeletal muscle glucose transport in vitro. Acta Physiol Scand 1991, 143:381-386.

18. Archuleta TL, Lemieux AM, Saengsirisuwan V, Teachey MK, Lindborg KA, Kim JS, Henriksen EJ: Oxidant stress-induced loss of IRS-1 and IRS-2 proteins in rat skeletal muscle: role of p38 MAPK. Free Radic Biol Med 2009, 47:1486-1493.

19. Houstis N, Rosen ED, Lander ES: Reactive oxygen species have a causa role in multiple forms of insulin resistance. Nature 2006, 440:944-948.

20. Gao D, Griffiths HR, Bailey CJ: Oleate protects against palmitate-induced insulin resistance in L6 myotubes. Br J Nutr 2009, 102:1557-1563.

21. Goodarzi MT, Navidi AA, Rezaei M, Babahmadi-Rezaei H: Oxidative damage to DNA and lipids: correlation with protein glycation in patients with type 1 diabetes. J Clin Lab Anal 2010, 24:72-76.

22. Dandona P, Thusu K, Cook S, Snyder B, Makowski J, Armstrong D, Nicotera T: Oxidative damage to DNA in diabetes mellitus. Lancet 1996, 347:444-445.

23. Keaney JF Jr, Larson MG, Vasan RS, Wilson PW, Lipinska I, Corey D, Massaro JM, Sutherland P, Vita JA, Benjamin EJ: Obesity and systemic oxidative stress: clinical correlates of oxidative stress in the Framingham Study. Arterioscler Thromb Vasc Biol 2003, 23:434-439.

24. Jain SK: Hyperglycemia can cause membrane lipid peroxidation and osmotic fragility in human red blood cells. J Biol Chem 1989, 264:21340-21345.

25. Jain SK, Levine SN, Duett J, Hollier B: Elevated lipid peroxidation levels in red blood cells of streptozotocin-treated diabetic rats. Metabolism 1990, 39:971-975.

26. Al-Aubaidy $\mathrm{H}$, Jelinek $\mathrm{H}$ : Oxidative DNA damage and obesity in type 2 diabetes mellitus. Eur J Endocrinol 2011, 164:899-905.

27. Tinahones FJ, Murri-Pierri M, Garrido-Sanchez L, Garcia-Almeida JM, Garcia-Serrano S, Garcia-Arnes J, Garcia-Fuentes E: Oxidative stress in severely obese persons is greater in those with insulin resistance. Obesity 2008, 17:240-246.

28. Jain SK: Glutathione and glucose-6-phosphate dehydrogenase deficiency can increase protein glycosylation. Free Radic Biol Med 1998, 24:197-201.

29. Jain SK, Levine SN, Duett J, Hollier B: Reduced vitamin E and increased lipofuscin products in erythrocytes of diabetic rats. Diabetes 1991, 40:1241-1244

30. Samiec PS, Drews-Botsch C, Flagg EW, Kurtz JC, Sternberg P Jr, Reed RL, Jones DP: Glutathione in human plasma: decline in association with aging, age-related macular degeneration, and diabetes. Free Radic Biol Med 1998, 24:699-704.

31. Marra G, Cotroneo P, Pitocco D, Manto A, Di Leo MA, Ruotolo V, Caputo S, Giardina B, Ghirlanda G, Santini SA: Early increase of oxidative stress and reduced antioxidant defenses in patients with uncomplicated type 1 diabetes: a case for gender difference. Diabetes Care 2002, 25:370-375 
32. Kesavulu MM, Giri R, Kameswara Rao B, Apparao C: Lipid peroxidation and antioxidant enzyme levels in type 2 diabetics with microvascular complications. Diabetes Metab 2000, 26:387-392

33. Nuttall SL, Dunne F, Kendall MJ, Martin U: Age-independent oxidative stress in elderly patients with non-insulin-dependent diabetes mellitus. QJM 1999, 92:33-38.

34. Mendoza-Nunez VM, Rosado-Perez J, Santiago-Osorio E, Ortiz R, Sanchez Rodriguez MA, Galvan-Duarte RE: Aging linked to type 2 diabetes increases oxidative stress and chronic inflammation. Rejuvenation Res 2011, 14:25-31.

35. Pandi KB, Rivzi SI: Age-dependent oxidative stress biomarkers in Type 2 diabetic patients. J Human Dis 2011, 1:8.

36. Wu J, Mei C, Vlassara H, Striker GE, Zheng F: Oxidative stress-induced JNK activation contributes to proinflammatory phenotype of aging diabetic mesangial cells. Am J Physiol Renal Physiol 2009, 297:F1622-F1631.

37. Rowe JW, Minaker KL, Pallotta JA, Flier JS: Characterization of the insulin resistance of aging. J Clin Invest 1983, 71:1581-1587

38. Furukawa S, Fujita T, Shimabukuro M, Iwaki M, Yamada Y, Nakajima Y, Nakayama O, Makishima M, Matsuda M, Shimomura I: Increased oxidative stress in obesity and its impact on metabolic syndrome. J Clin Invest 2004, 114:1752-1761.

39. Grimsrud PA, Picklo MJ, Griffin TJ, Bernlohr DA: Carbonylation of adipose proteins in obesity and insulin resistance. Mol Cell Proteomics 2007, 6:624-637.

40. Bonnard C, Durand A, Peyrol S, Chanseaume E, Chauvin M-A, Morio B, Vidal $H$, Rieusset J: Mitochondrial dysfunction results from oxidative stress in the skeletal muscle of diet-induced insulin-resistant mice. J Clin Invest 2008, 118:789-800.

41. Milagro Fl, Campion J, Martinez JA: Weight gain induced by high-fat feeding involves increased liver oxidative stress. Obesity (Silver Spring) 2006, 14:1118-1123.

42. Anderson EJ, Lustig ME, Boyle KE, Woodlief TL, Kane DA, Lin C-T, Price JW, Kang L, Rabinovitch PS, Szeto HH, et al: Mitochondrial H2O2 emission and cellular redox state link excess fat intake to insulin resistance in both rodents and humans. J Clin Invest 2009, 119:573-581.

43. Yokota T, Kinugawa S, Hirabayashi K, Matsushima S, Inoue N, Ohta Y, Hamaguchi S, Sobirin MA, Ono T, Suga T, et al: Oxidative stress in skeletal muscle impairs mitochondrial respiration and limits exercise capacity in type 2 diabetic mice. Am J Physiol Heart Circ Physiol 2009, 297:H1069-H1077.

44. Frohnert BI, Sinaiko AR, Serrot FJ, Foncea RE, Moran A, Ikramuddin S, Choudry U, Bernlohr DA: Increased adipose protein carbonylation in human obesity. Obesity 2011, 19:1735-1741.

45. Russell AP, Gastaldi G, Bobbioni-Harsch E, Arboit P, Gobelet C, Dériaz O, Golay A, Witztum JL, Giacobino J-P: Lipid peroxidation in skeletal muscle of obese as compared to endurance-trained humans: a case of good vs. bad lipids? FEBS Lett 2003, 551:104-106.

46. Bokov A, Chaudhuri A, Richardson A: The role of oxidative damage and stress in aging. Mech Ageing Dev 2004, 125:811-826.

47. Mansouri A, Muller FL, Liu Y, Ng R, Faulkner J, Hamilton M, Richardson A Huang T-T, Epstein CJ, Van Remmen H: Alterations in mitochondrial function, hydrogen peroxide release and oxidative damage in mouse hind-limb skeletal muscle during aging. Mech Ageing Dev 2006, 127:298-306.

48. Hamilton ML, Van Remmen H, Drake JA, Yang H, Guo ZM, Kewitt K, Walter CA, Richardson A: Does oxidative damage to DNA increase with age? Proc Natl Acad Sci 2001, 98:10469-10474.

49. Muller FL, Song W, Liu Y, Chaudhuri A, Pieke-Dahl S, Strong R, Huang TT, Epstein CJ, Roberts $L J$ 2nd, Csete $M$, et al: Absence of CuZn superoxide dismutase leads to elevated oxidative stress and acceleration of age-dependent skeletal muscle atrophy. Free Radic Biol Med 2006, 40:1993-2004

50. Marzani B, Pansarasa O: "Oxidative stress" and muscle aging: influence of age, sex, fiber composition and function. Basic Appl Myol 2004, 14:37-44.

51. Navarro A, Boveris A: Rat brain and liver mitochondria develop oxidative stress and lose enzymatic activities on aging. Am J Physiol Regul Integr Comp Physiol 2004, 287:R1244-R1249.

52. Lopez-Torres M, Gredilla R, Sanz A, Barja G: Influence of aging and long-term caloric restriction on oxygen radical generation and oxidative DNA damage in rat liver mitochondria. Free Radic Biol Med 2002, 32:882-889.
53. Zhang L, Ebenezer PJ, Dasuri K, Fernandez-Kim SO, Francis J, Mariappan N, Gao Z, Ye J, Bruce-Keller A, Keller JN: Aging is associated with hypoxia and oxidative stress in adipose tissue: Implications for adipose function. American Journal of Physiology - Endocrinology And Metabolism 2011, 301:E599-E607.

54. Sackmann-Sala L, Berryman D, Lubbers E, Vesel C, Troike K, List E, Munn R, Ikeno $Y$, Kopchick J: Decreased insulin sensitivity and increased oxidative damage in wasting adipose tissue depots of wild-type mice. Age, (1):13. in press.

55. Findeisen HM, Pearson KJ, Gizard F, Zhao Y, Qing H, Jones KL, Cohn D, Heywood EB, de Cabo R, Bruemmer D: Oxidative stress accumulates in adipose tissue during aging and inhibits adipogenesis. PLOS One 2011, 6:e18532.

56. Lenzen S, Drinkgern J, Tiedge M: Low antioxidant enzyme gene expression in pancreatic islets compared with various other mouse tissues. Free Radic Biol Med 1996, 20:463-466.

57. Grankvist K, Marklund SL, Taljedal IB: CuZn-superoxide dismutase, Mn-superoxide dismutase, catalase and glutathione peroxidase in pancreatic islets and other tissues in the mouse. Biochem J 1981 , 199:393-398.

58. Pi J, Bai Y, Zhang Q, Wong V, Floering LM, Daniel K, Reece JM, Deeney JT, Andersen ME, Corkey BE, Collins S: Reactive oxygen species as a signal in glucose-stimulated insulin secretion. Diabetes 2007, 56:1783-1791.

59. Leloup C, Tourrel-Cuzin C, Magnan C, Karaca M, Castel J, Carneiro L, Colombani A-L, Ktorza A, Casteilla L, Pénicaud L: Mitochondrial reactive oxygen species are obligatory signals for glucose-induced insulin secretion. Diabetes 2009, 58:673-681.

60. Coskun O, Kanter M, Korkmaz A, Oter S: Quercetin, a flavonoid antioxidant, prevents and protects streptozotocin-induced oxidative stress and $\beta$-cell damage in rat pancreas. Pharmacol Res 2005, 51:117-123.

61. Sano T, Umeda F, Hashimoto T, Nawata H, Utsumi H: Oxidative stress measurement by in vivo electron spin resonance spectroscopy in rats with streptozotocin-induced diabetes. Diabetologia 1998, 41:1355-1360.

62. Grankvist K, Marklund S, Taljedal I-B: Superoxide dismutase is a prophylactic against alloxan diabetes. Nature 1981, 294:158-160

63. Harmon JS, Bogdani M, Parazzoli SD, Mak SSM, Oseid EA, Berghmans M, LeBoeuf RC, Robertson RP: $\beta$-cell-specific overexpression of glutathione peroxidase preserves intranuclear MafA and reverses diabetes in $\mathrm{db} / \mathrm{db}$ mice. Endocrinology 2009, 150:4855-4862.

64. Ihara Y, Toyokuni S, Uchida K, Odaka H, Tanaka T, Ikeda H, Hiai H, Seino Y, Yamada Y: Hyperglycemia causes oxidative stress in pancreatic beta-cells of GK rats, a model of type 2 diabetes. Diabetes 1999, 48:927-932.

65. Sakuraba H, Mizukami H, Yagihashi N, Wada R, Hanyu C, Yagihashi S: Reduced beta-cell mass and expression of oxidative stress-related DNA damage in the islet of Japanese Type II diabetic patients. Diabetologia 2002, 45:85-96.

66. Tchkonia T, Morbeck DE, Von Zglinicki T, Van Deursen J, Lustgarten J, Scrable H, Khosla S, Jensen MD, Kirkland JL: Fat tissue, aging, and cellular senescence. Aging Cell 2010, 9:667-684.

67. Morin CL, Pagliassotti MJ, Windmiller D, Eckel RH: Adipose tissue-derived tumor necrosis factor-alpha activity is elevated in older rats. $J$ Gerontol A Biol Sci Med Sci 1997, 52:B190-B195.

68. Starr ME, Evers BM, Saito H: Age-associated increase in cytokine production during systemic inflammation: adipose tissue as a major source of IL-6. J Gerontol A Biol Sci Med Sci 2009, 64:723-730.

69. Tchkonia T, Pirtskhalava T, Thomou T, Cartwright MJ, Wise B, Karagiannides I, Shpilman A, Lash TL, Becherer JD, Kirkland JL: Increased TNFalpha and CCAAT/enhancer-binding protein homologous protein with aging predispose preadipocytes to resist adipogenesis. Am J Physiol Endocrinol Metab 2007, 293:E1810-E1819.

70. Jang YC, Perez VI, Song W, Lustgarten MS, Salmon AB, Mele J, Qi W, Liu Y, Liang $H$, Chaudhuri $A$, et al: Overexpression of Mn superoxide dismutase does not increase life span in mice. J Gerontol A Biol Sci Med Sci 2009, 64:1114-1125

71. Hotamisligil GS: Inflammation and metabolic disorders. Nature 2006, 444:860-867.

72. Aguirre V, Uchida T, Yenush L, Davis R, White MF: The c-Jun NH2-terminal Kinase promotes insulin resistance during association with insulin receptor substrate-1 and Phosphorylation of Ser307. J Biol Chem 2000, 275:9047-9054. 
73. Aguirre V, Werner ED, Giraud J, Lee YH, Shoelson SE, White MF: Phosphorylation of Ser307 in insulin receptor substrate-1 blocks interactions with the insulin receptor and inhibits insulin action. J Biol Chem 2002, 277:1531-1537.

74. Kamata H, Honda S, Maeda S, Chang L, Hirata H, Karin M: Reactive oxygen species promote TNFalpha-induced death and sustained JNK activation by inhibiting MAP kinase phosphatases. Cell 2005, 120:649-661.

75. Adler V, Yin Z, Fuchs SY, Benezra M, Rosario L, Tew KD, Pincus MR, Sardana M, Henderson CJ, Wolf CR, et al: Regulation of JNK signaling by GSTp. EMBO J 1999, 18:1321-1334.

76. Liu H, Nishitoh $H$, Ichijo H, Kyriakis JM: Activation of apoptosis signal-regulating kinase 1 (ASK1) by tumor necrosis factor receptor-associated factor 2 requires prior dissociation of the ASK1 inhibitor thioredoxin. Mol Cell Biol 2000, 20:2198-2208.

77. Hirosumi J, Tuncman G, Chang L, Gorgun CZ, Uysal KT, Maeda K, Karin M, Hotamisligil GS: A central role for JNK in obesity and insulin resistance. Nature 2002, 420:333-336.

78. Nakatani Y, Kaneto H, Kawamori D, Hatazaki M, Miyatsuka T, Matsuoka TKajimoto Y, Matsuhisa M, Yamasaki Y, Hori M: Modulation of the JNK pathway in liver affects insulin resistance status. J Biol Chem 2004, 279:45803-45809.

79. Williamson D, Gallagher P, Harber M, Hollon C, Trappe S: Mitogen-activated protein kinase (MAPK) pathway activation: effects of age and acute exercise on human skeletal muscle. J Physiol 2003, 547:977-987.

80. Hsieh C-C, Rosenblatt J, Papaconstantinou J: Age-associated changes in SAPK/JNK and p38 MAPK signaling in response to the generation of ROS by 3-nitropropionic acid. Mech Ageing Dev 2003, 124:733-746.

81. Chung HY, Cesari M, Anton S, Marzetti E, Giovannini S, Seo AY, Carter C, Yu BP, Leeuwenburgh C: Molecular inflammation: Underpinnings of aging and age-related diseases. Ageing Res Rev 2009, 8:18-30.

82. Shoelson SE, Lee J, Goldfine AB: Inflammation and insulin resistance. J Clin Invest 2006, 116:1793-1801.

83. Sung FL, Zhu TY, Au-Yeung KKW, Siow YL, Karmin O: Enhanced MCP-1 expression during ischemia/reperfusion injury is mediated by oxidative stress and NF-kB. Kidney Int 2002, 62:1160-1170.

84. Rahman I, Gilmour PS, Jimenez LA, MacNee W: Oxidative stress and TNF-alpha induce histone acetylation and NF-kappaB/AP-1 activation in alveolar epithelial cells: potential mechanism in gene transcription in lung inflammation. Mol Cell Biochem 2002, 234-235:239-248.

85. Park J, Choe SS, Choi AH, Kim KH, Yoon MJ, Suganami T, Ogawa Y, Kim JB: Increase in glucose-6-phosphate dehydrogenase in adipocytes stimulates oxidative stress and inflammatory signals. Diabetes 2006 55:2939-2949.

86. Minamino T, Orimo M, Shimizu I, Kunieda T, Yokoyama M, Ito T, Nojima A, Nabetani A, Oike $Y$, Matsubara $H$, et al: A crucial role for adipose tissue p53 in the regulation of insulin resistance. Nat Med 2009, 15:1082-1087.

87. Kirkland JL, Tchkonia T, Pirtskhalava T, Han J, Karagiannides I: Adipogenesis and aging: does aging make fat go MAD? Exp Gerontol 2002, 37:757-767.

88. Coppé J-P, Patil CK, Rodier F, Sun Y, Muñoz DP, Goldstein J, Nelson PS, Desprez P-Y, Campisi J: Senescence-associated secretory phenotypes reveal cell-nonautonomous functions of oncogenic RAS and the p53 tumor suppressor. PLoS Biol 2008, 6:e301.

89. Hotamisligil GS, Shargill NS, Spiegelman BM: Adipose expression of tumor necrosis factor-alpha: direct role in obesity-linked insulin resistance. Science 1993, 259:87-91.

90. Hotamisligil GS, Peraldi P, Budavari A, Ellis R, White MF, Spiegelman BM: IRS-1-mediated inhibition of insulin receptor tyrosine kinase activity in TNF-alpha- and obesity-induced insulin resistance. Science 1996 271:665-668.

91. Phillips T, Leeuwenburgh C: Muscle fiber-specific apoptosis and TNF-a signaling in sarcopenia are attenuated by life-long calorie restriction. FASEB J 2005, 19:668-670.

92. Kirwan JP, Krishnan RK, Weaver JA, Del Aguila LF, Evans WJ: Human aging is associated with altered TNF-a production during hyperglycemia and hyperinsulinemia. American Journal of Physiology - Endocrinology And Metabolism 2001, 281:E1137-E1143.

93. Bertelsen $M$, Anggard EE, Carrier MJ: Oxidative stress impairs insulin internalization in endothelial cells in vitro. Diabetologia 2001, 44:605-613.

94. Van den Dobbelsteen DJ, Toxopeus C, van Holsteijn CWM, Nooy HA, Droog Cl, Horbach GJMJ, Noordhoek J, Blaauboer BJ: Effect of alkylating and redox cycling quinones on insulin receptor autophosphorylation. Toxicol Vitr 1994, 8:563-567.

95. Zhou J, He X, Huang K: Bidirectional regulation of insulin receptor autophosphorylation and kinase activity by peroxynitrite. Arch Biochem Biophys 2009, 488:1-8.

96. Tirosh A, Potashnik R, Bashan N, Rudich A: Oxidative stress disrupts insulininduced cellular redistribution of insulin receptor substrate- 1 and phosphatidylinositol 3-kinase in 3T3-L1 adipocytes. A putative cellular mechanism for impaired protein kinase B activation and GLUT4 translocation. J Biol Chem 1999, 274:10595-10602

97. Pessler D, Rudich A, Bashan N: Oxidative stress impairs nuclear proteins binding to the insulin responsive element in the GLUT4 promoter. Diabetologia 2001, 44:2156-2164.

98. Bolinder J, Ostman J, Arner P: Influence of aging on insulin receptor binding and metabolic effects of insulin on human adipose tissue. Diabetes 1983, 32:959-964.

99. Levine RL: Oxidative modification of glutamine synthetase. I. Inactivation is due to loss of one histidine residue. J Biol Chem 1983, 258:11823-11827.

100. Cabiscol E, Levine RL: Carbonic Anhydrase III. Oxidative modification in vivo and loss of phosphatase activity during aging. J Biol Chem 1995, 270:14742-14747.

101. Hoehn KL, Salmon AB, Hohnen-Behrens C, Turner N, Hoy AJ, Maghzal GJ, Stocker R, Van Remmen H, Kraegen EW, Cooney GJ, et al: Insulin resistance is a cellular antioxidant defense mechanism. Proc Natl Acad Sci 2009, 106:17787-17792

102. Chen L, Na R, Gu M, Salmon AB, Liu Y, Liang H, Qi W, Van Remmen H, Richardson A, Ran Q: Reduction of mitochondrial $\mathrm{H} 2 \mathrm{O} 2$ by overexpressing peroxiredoxin 3 improves glucose tolerance in mice. Aging Cell 2008, 7:866-878.

103. Lee HY, Choi CS, Birkenfeld AL, Alves TC, Jornayvaz FR, Jurczak MJ, Zhang D, Woo DK, Shadel GS, Ladiges W, et al: Targeted expression of catalase to mitochondria prevents age-associated reductions in mitochondrial function and insulin resistance. Cell Metab 2010, 12:668-674

104. Moustafa SA, Webster JE, Mattar FE: Effects of aging and antioxidants on glucose transport in rat adipocytes. Gerontology 1995, 41:301-307.

105. Ceriello A, Testa R: Antioxidant anti-inflammatory treatment in type 2 diabetes. Diabetes Care 2009, 32:\$232-\$236.

106. Golbidi S, Ebadi SA, Laher I: Antioxidants in the treatment of diabetes. Curr Diabetes Rev 2011, 7:106-125

107. Johansen JS, Harris AK, Rychly DJ, Ergul A: Oxidative stress and the use of antioxidants in diabetes: linking basic science to clinical practice. Cardiovasc Diabetol 2005, 4:5

108. Nojima H, Watanabe $H$, Yamane $K$, Kitahara $Y$, Sekikawa K, Yamamoto $H_{\text {, }}$ Yokoyama A, Inamizu T, Asahara T, Kohno N: Effect of aerobic exercise training on oxidative stress in patients with type 2 diabetes mellitus. Metabolism 2008, 57:170-176.

109. Leeuwenburgh C, Heinecke JW: Oxidative stress and antioxidants in exercise. Curr Med Chem 2001, 8:829-838.

110. Radak Z, Naito H, Kaneko T, Tahara S, Nakamoto H, Takahashi R, Cardozo-Pelaez F, Goto S: Exercise training decreases DNA damage and increases DNA repair and resistance against oxidative stress of proteins in aged rat skeletal muscle. Pflugers Arch 2002, 445:273-278.

111. Folmer V, Soares JCM, Rocha JBT: Oxidative stress in mice is dependent on the free glucose content of the diet. Int J Biochem Cell Biol 2002, 34:1279-1285.

112. Nangaku M, Izuhara $Y$, Usuda $N$, Inagi $R$, Shibata $T$, Sugiyama $S$, Kurokawa $K$, Van Ypersele de Strihou C, Miyata T: In a type 2 diabetic nephropathy rat model, the improvement of obesity by a low calorie diet reduces oxidative/carbonyl stress and prevents diabetic nephropathy. Nephrol Dial Transplant 2005, 20:2661-2669.

113. Roberts CK, Vaziri ND, Barnard RJ: Effect of diet and exercise intervention on blood pressure, insulin, oxidative stress, and nitric oxide availability. Circulation 2002, 106:2530-2532.

\section{doi:10.1186/2046-2395-1-7}

Cite this article as: Salmon: Oxidative stress in the etiology of ageassociated decline in glucose metabolism. Longevity \& Healthspan 2012 $1: 7$. 